\title{
Effect of Zincate Treatment on Adhesion of Electroless Ni-P Coating onto Various Aluminum Alloys*1
}

\author{
Makoto Hino $^{1}$, Koji Murakami ${ }^{1}$, Yutaka Mitooka ${ }^{1}$, Ken Muraoka ${ }^{1}$, \\ Ryosuke Furukawa $^{2, * 2}$ and Teruto Kanadani ${ }^{2}$ \\ ${ }^{1}$ Industrial Technology Research Institute of Okayama Prefecture, Okayama 701-1296, Japan \\ ${ }^{2}$ Faculty of Engineering, Okayama University of Science, Okayama 700-0005, Japan
}

\begin{abstract}
It is well known that the adhesion of the electroless Ni-P coating on aluminum alloy substrate can be remarkably improved by introducing the double zincate treatment as a pretreatment process. This study investigated the effects of the alloying element and zincate treatment on adhesion of electroless Ni-P coating on various aluminum alloy substrates using peeling test, FE-SEM and XPS. Surface morphology of zinc deposit from the 1 st zincate treatment and its adhesive strength were changed, depending on the alloying element. The zinc deposit from the 2 nd zincate treatment became uniformly thin, and the adhesive strength was improved irrespective of the alloying element. By dipping the zinc deposit obtained at the 1 st zincate in $5 \% \mathrm{HNO}_{3}$ solution, most of the zinc deposit on aluminum substrate was dissolved, but XPS analysis revealed that the existence of zinc, whose state was metal, at the surface of aluminum alloy substrate after this dipping. This zinc at the surface should be an important factor influencing morphology of zinc deposit at the 2nd zincate treatment, so that zinc deposit became highly uniform and thin. This zinc at the surface can be attributed to the diffusion of zinc and aluminum between the zinc deposit from the 1 st zincate and the aluminum alloy substrate. [doi:10.2320/matertrans.L-M2009819]
\end{abstract}

(Received February 18, 2009; Accepted May 20, 2009; Published July 29, 2009)

Keywords: electroless Ni-P coating, aluminum alloy, zincate treatment, adhesion

\section{Introduction}

Recently, aluminum alloys are increasingly being used to improve fuel consumption of vehicles by reducing their weight, along with their excellent workability and corrosion resistance. ${ }^{1)}$ In order to improve their surface properties, plating onto aluminum alloys has been commonly adopted. ${ }^{2)}$ Since aluminum is such an active element and is passivated by oxidation in water as well as in air, the loss of adhesion of the plated film on the aluminum alloy substrate due to the oxide film is one of the problems of this process. For this purpose, zincate treatment is commonly adopted which covers the surface of the substrate with a zinc film by a displacement reaction of the aluminum and zinc. Especially, the double zincate treatment, ${ }^{3)}$ which repeats the conversion treatment twice, shows a remarkable increase in adhesive strength. However, the mechanism for improving the adhesion by the double zincate treatment is not clear.

In a few previous studies ${ }^{4-7)}$ on the double zincate treatment for aluminum alloy substrates, the morphology of the zinc deposits was thin and uniform, and interdiffusion of the aluminum and nickel between the Ni-P plated film and the aluminum substrate was thought to promote the strong bond. Although the zinc deposits became thin and uniform by introducing the double zincate treatment, which consists of repeating the conversion treatment, its detailed mechanism remains unknown.

In this study, the effects of alloying elements and pretreatment, such as the number of zincate treatments and the type of the acid after the 1st zincate treatment on adhesion of the electroless Ni-P coating onto various aluminum alloys

\footnotetext{
${ }^{* 1}$ This Paper was Originally Published in Japanese in J. Japan Inst. Light Metals 58 (2008) 516-521.

${ }^{* 2}$ Graduate Student, Okayama University of Science. Present address: Yodogawa Steel Works, Ltd., Osaka 555-0044, Japan
}

substrates were investigated using the peeling test, Field Emission Scanning Electron Microscope (FE-SEM) and $\mathrm{X}$-ray Photoelectron Spectroscopy (XPS). In addition, the mechanism of zinc deposition which became uniformly thin by introducing the double zincate treatment was discussed.

\section{Experimental Procedure}

Three kinds of rolled aluminum alloys $\left(30 \times 10 \times 1^{\mathrm{t}} \mathrm{mm}\right)$ were used as substrate whose chemical compositions are shown in Table 1. These substrates were polished to a mirror finish by buffing in order to eliminate the anchoring effect. ${ }^{8)}$ Prior to the electroless Ni-P platings, various pretreatments were carried out according to Table 2 . The mixed acid (1 $\mathrm{HF}($ Concentration: $46 \%)+3 \mathrm{HNO}_{3} \quad$ (Concentration:60\%)) dipping treatment was newly added instead of the conversion treatment by $5 \%$ nitric acid dipping for pickling after the 1 st zincate treatment in order to clarify the effect of the zincate treatment on the adhesion of the Ni-P plated films in this investigation. A commercial zincate solution (Japan KANIGEN Co. Ltd., SUMER K-102) and an electroless Ni-P plating solution (Japan KANIGEN Co. Ltd., SD-200) were used for the treatments. Each zincate treatment was carried out at $298 \mathrm{~K}$ for $30 \mathrm{~s}$, and the electroless Ni-P plating at $363 \pm 3 \mathrm{~K}$ for $7.2 \mathrm{ks}$. The content of phosphorus and the average thickness of the Ni-P coating obtained under the above conditions were $9 \pm 0.5$ mass $\%$ and $20 \mu \mathrm{m}$, respectively.

Table 1 Chemical compositon of various aluminum alloys. (mass\%)

\begin{tabular}{ccccccccccc}
\hline & $\mathrm{Si}$ & $\mathrm{Fe}$ & $\mathrm{Cu}$ & $\mathrm{Mn}$ & $\mathrm{Mg}$ & $\mathrm{Cr}$ & $\mathrm{Zn}$ & $\mathrm{Ti}$ & $\begin{array}{c}\text { Others } \\
\text { total }\end{array}$ & $\mathrm{Al}$ \\
\hline $\mathrm{A} 1100 \mathrm{P}$ & 0.12 & 0.57 & 0.12 & 0 & 0 & 0 & 0.01 & 0 & 0.05 & bal. \\
\hline A2017P & 0.54 & 0.27 & 3.33 & 0.6 & 0.53 & 0.02 & 0.12 & 0.03 & 0.01 & bal. \\
\hline A5052P & 0.09 & 0.27 & 0.04 & 0.1 & 2.47 & 0.22 & 0.01 & 0 & 0.03 & bal. \\
\hline
\end{tabular}


Table 2 Various pretreatments and zincate proceduers.

\begin{tabular}{|c|c|c|c|c|}
\hline Without zincate & 1st zincate & 2nd zincate & 2nd zincate(Pickling) & $\begin{array}{l}\text { 2nd zincate(Pickling) } \\
+ \text { zincate }\end{array}$ \\
\hline Alkaline cleaning & Alkaline cleaning & Single zincate & Single zincate & Double zincate(Pickling) \\
\hline Washing & Washing & $\begin{array}{c}5 \% \mathrm{HNO}_{3} \text { dipping } \\
\text { (Dipping: } 10 \mathrm{~s} \text { ) }\end{array}$ & $\begin{array}{c}\text { Pickling }\left(1 \mathrm{HF}+3 \mathrm{HNO}_{3}\right) \\
\text { (Dipping: } 10 \mathrm{~s})\end{array}$ & $\begin{array}{l}5 \% \mathrm{HNO}_{3} \text { dipping } \\
\text { (Dipping: } 10 \mathrm{~s} \text { ) }\end{array}$ \\
\hline $\begin{array}{c}\text { Pickling }\left(1 \mathrm{HF}+3 \mathrm{HNO}_{3}\right) \\
\text { (Dipping: } 10 \mathrm{~s})\end{array}$ & $\begin{array}{c}\text { Pickling }\left(1 \mathrm{HF}+3 \mathrm{HNO}_{3}\right) \\
\text { (Dipping: } 10 \mathrm{~s})\end{array}$ & Washing & Washing & Washing \\
\hline$\downarrow$ & $\downarrow$ & $\downarrow$ & $\downarrow$ & $\downarrow$ \\
\hline \multirow[t]{4}{*}{ Washing } & Washing & Zincate treatment $(30 \mathrm{~s})$ & Zincate treatment $(30 \mathrm{~s})$ & Zincate treatment $(30 \mathrm{~s})$ \\
\hline & $\downarrow$ & $\downarrow$ & $\downarrow$ & $\downarrow$ \\
\hline & $\downarrow$ & & & \\
\hline & Washing & & & \\
\hline
\end{tabular}

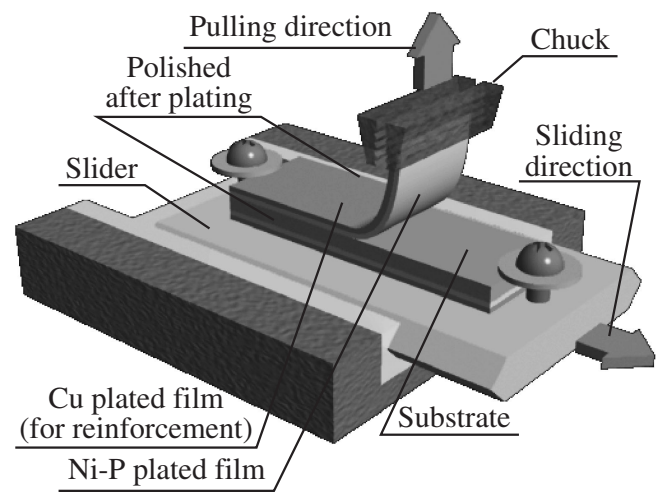

Fig. 1 Schematic illustration of the $90^{\circ}$ peeling test.

After the electroless Ni-P coating, a $90^{\circ}$ peeling test was carried out for quantification of the adhesive strength of the plated films to the substrates as shown in Fig. 1.4) Before the peeling test, the specimens were coated with a $30 \mu \mathrm{m}$-thick copper film by electroplating in a copper sulfate solution for reinforcement of the electroless Ni-P coating. The sides of the copper-coated substrates were polished to remove any unnecessary films for the peeling test, and then part of the coating was peeled from the edge of the substrate for chucking. The tensile test was then carried out on the substrate fixed on the slider in which the cross head speed was $0.5 \mathrm{~mm} / \mathrm{s}$. The morphology of the surfaces for the various pretreated substrates was observed by FE-SEM (Hitachi High-Technologies Co., model S-4700). The chemical state of the metallic pattern analysis on the surface dipped in various acids after the 1st zincate treatment was conducted by XPS (JEOL Co., model JPS-90MX MICRO, Mg-K $\alpha$, $10 \mathrm{kV}-10 \mathrm{~mA}$, analysis area: $6 \mathrm{~mm} \phi$ ). The analysis depth by XPS is several $\mathrm{nm}$.

\section{Results and Discussion}

\subsection{Each kind of zincate treatment and its adhesion strength}

Table 3 shows the adhesion strength for each pretreatment obtained by the peeling test. On the A1100P aluminum alloy
Table 3 Adhesion strength.

\begin{tabular}{cccc}
\hline \multirow{2}{*}{ Zincate treament } & \multicolumn{3}{c}{ Adhesion strength $[\mathrm{kN} / \mathrm{m}]$} \\
\cline { 2 - 4 } & A1100P & A2017P & A5052P \\
\hline Without zincate & No deposition & 0.07 & 0.04 \\
\hline 1st zincate & 0.52 & 0.13 & 0.06 \\
\hline 2nd zincate & Film rupture & 1.12 & 1.16 \\
\hline 2nd zincate(Pickling) & 0.75 & 0.67 & 0.16 \\
\hline $\begin{array}{c}\text { 2nd zincate(Pickling) } \\
+ \text { zincate }\end{array}$ & Film rupture & Film rupture & Film rupture \\
\hline
\end{tabular}

substrate, it was not possible to conduct the peeling test, since the Ni-P film could not be deposited without the zincate treatment. The Ni-P film deposited on the A2017P and A5052P substrates, and the adhesion strength of each film were quite poor. In spite of the same pretreatment for each specimen, the film on the A1100P substrate could not be deposited, this factor seemed to be based on the difference in the oxide film formed on each substrate. Since the oxide film formed on the A1100P substrate, whose alloy element content is very low, is more uniformly thick than those on the A2017P and A5052P substrates containing alloy elements, such as copper and magnesium, after the mixed acid dipping treatment, the electrochemical reaction in the zincate solution seems to be suppressed. Therefore, the zinc displacement reaction is not generated. In a previous study, ${ }^{7}$ these oxide films formed on each substrate after the mixed acid dipping treatment affect the morphology of zinc deposits for the 1st zincate treatment.

The adhesion strength of each specimens was only slightly improved after the 1st zincate treatment, however, that of each specimen after the 2nd zincate treatment was drastically improved. In particular, a film on the A1100P alloy showed a firm adherence as the film ruptured. In this way, the double zincate treatment plays an important role in the adhesion of the Ni-P film on aluminum alloy substrates. However, in spite of the same zincate treatment, the adhesion of the film significantly varied, depending on the type of alloy type, and these results suggested that the alloying element was 


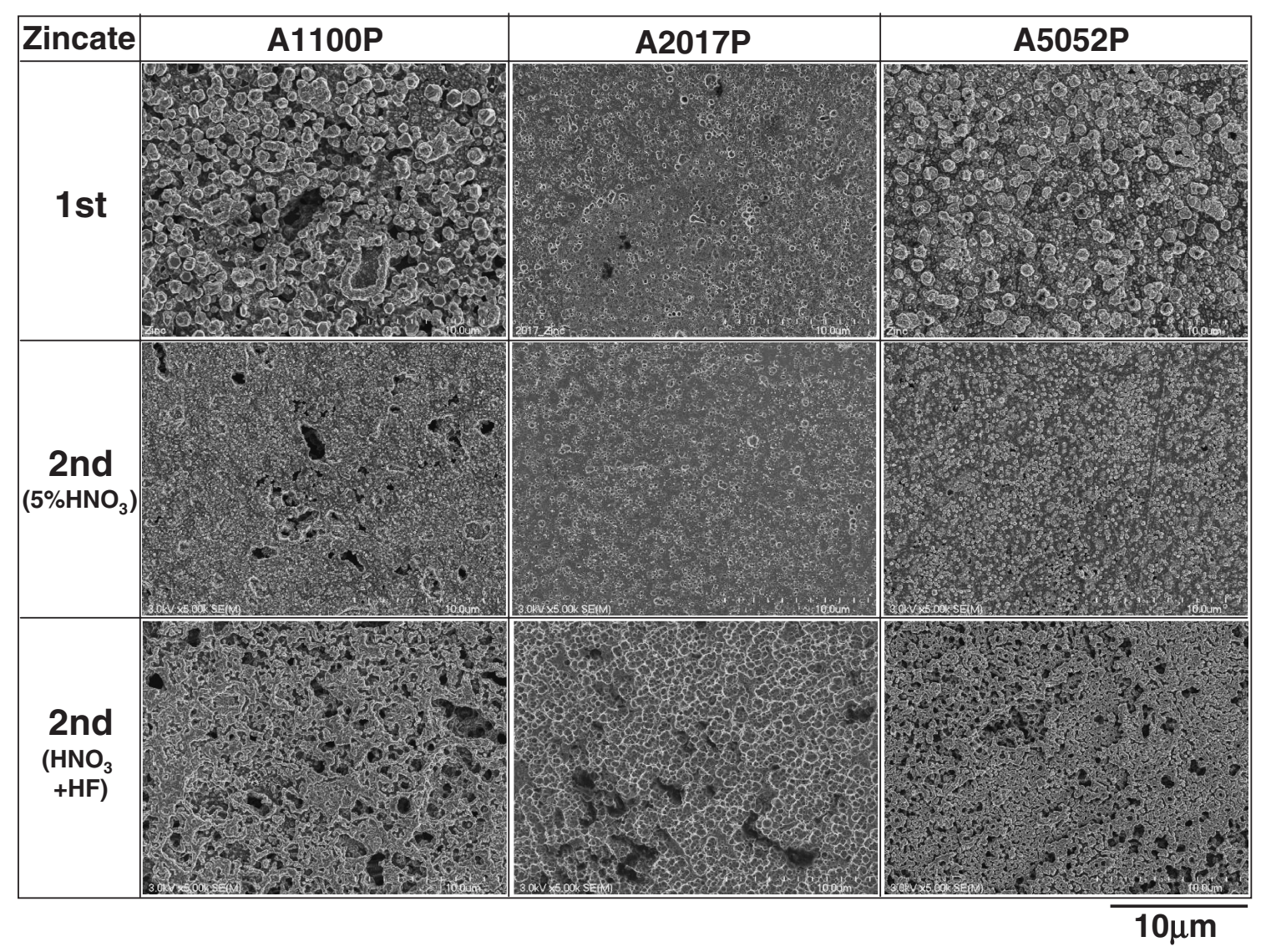

Fig. 2 SEM images of specimens showing zincate treated surface of various aluminum alloys.

intimately related to the adhesion. Previous research ${ }^{9)}$ has indicated that the adhesion strength of the Ni-P film on the A7075P aluminum alloy substrate with the double zincate treatment was remarkably reduced. The reason why this marked degradation of the adhesion strength is unknown, and a further investigation is required to fully understand this phenomenon in the future.

As a mixed acid $\left(1 \mathrm{HF}+3 \mathrm{HNO}_{3}\right)$, shown in Table 2, was used instead of $5 \%$ nitric acid for the pickling after the 1 st zincate treatment, the adhesion strength of each specimen after the 2nd zincate treatment decreased, and the $10 \%$ hydrochloric acid instead of the mixed acid for the pickling also reduced the adhesion strength of each specimen. However, the adhesion of the foregoing specimens, which used the 5\% nitric acid for the pickling and zincate treatment again, was drastically improved as the film ruptured. These results indicate that the adhesion of the film after the 2nd zincate treatment depended on the type of acid for removal of the zinc deposit by a displacement reaction during the $1 \mathrm{st}$ zincate treatment.

Figure 2 shows the SEM images of the surface of the zinc deposits after the zincate treatment with the various pretreatments shown in Table 2. Although the morphology of the zinc deposits after the 1st zincate treatment was different depending on the alloy type, nonuniform rough deposits were observed besides the A2017P alloy. In a previous report, ${ }^{9)}$ it was shown that this uniform and fine zinc deposit on the A2017P alloy after the 1st zincate treatment was attributed to copper enrichment at the substrate surface after the pickling $\left(1 \mathrm{HF}+3 \mathrm{HNO}_{3}\right)$. The surface of each substrate by the 2 nd zincate treatment with the dipping in 5\% nitric acid was then uniformly covered by fine deposits.

On the other hand, when a mixed acid $\left(1 \mathrm{HF}+3 \mathrm{HNO}_{3}\right)$ was used instead of the 5\% nitric acid for the pickling after the 1st zincate treatment, zinc deposits, comparable to the pickling by the $5 \%$ nitric acid, became nonuniformly rough. From the results of Table 3 and Fig. 2, the adhesion strength is closely associated with the morphology of the zinc deposits treated by the zincate process.

Figure 3 shows the SEM images of the specimen surface after various the picklings shown in Table 2 on various aluminum alloys. Multiple pits partially occurred due to the pretreatment, such as alkaline cleaning and pickling $\left(1 \mathrm{HF}+3 \mathrm{HNO}_{3}\right)$ on each substrate surface after mirror finishing, but it was possible to still observe the scratches formed during the mirror finishing. The surface morphology of the 1 st zincate treatment after the pickling by $5 \%$ nitric acid, was comparable to the surface morphology before that, roughened together with a number of pits, whereas the surface morphology with the pickling by the mixed acid became rougher than that of the pickling by the $5 \%$ nitric acid. Azumi reported that the anchor effect based on the surface roughness produced by the dissolution of the aluminum and precipitation of zinc made the adhesion improve. ${ }^{10)}$ However, from these results showing a further reduction of the adhesion with the increasing surface roughness by the pickling using the mixed acid after the 1 st zincate treatment, it is strongly indicated that the morphology of the zinc deposit is an important factor for the adhesion, except for the anchor effect based on the surface roughness. In 


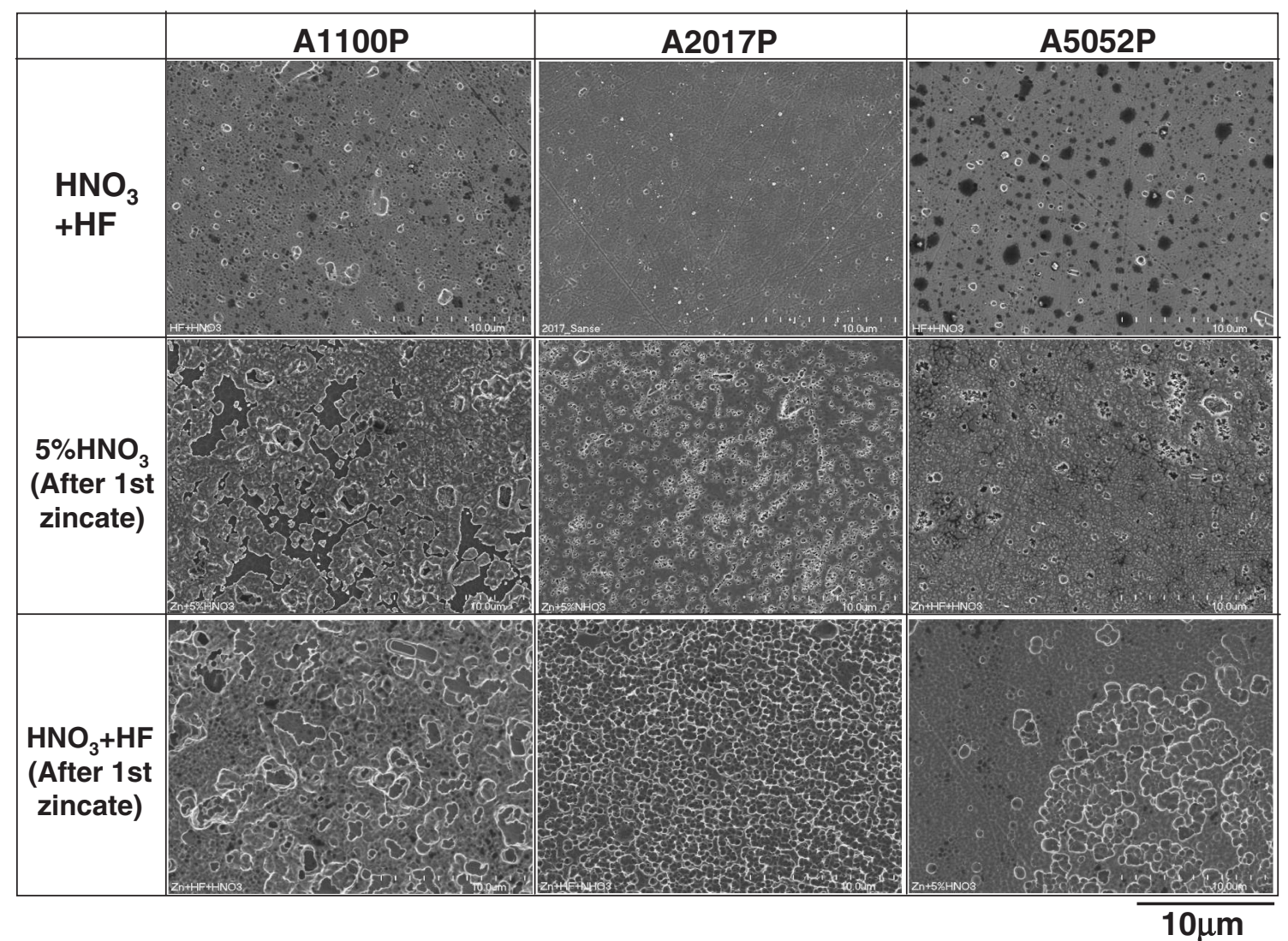

Fig. 3 SEM images of specimens showing the surface after various picklings of various aluminum alloys.

addition, since the pickling by the $5 \%$ nitric acid and zincate treatment were conducted again for the specimens with a poor adhesion using the mixed acid for the pickling, the adhesion of all specimens was drastically improved as the film ruptured. The zinc deposits after this treatment then became uniformly thin, like that of the 2 nd zincate treatment.

From the results of the SEM observations shown in Fig. 3, pits in each substrate surface increased due to the two picklings $\left(1 \mathrm{HF}+3 \mathrm{HNO}_{3}\right)$, in particular, the surfaces of the A1100P and A2017P alloy substrates were fairly etched as the scratches formed in the mirror finishing disappeared. It seems that the anchor effect on the basis of this surface roughness makes the adhesion improve as the film ruptured.

\subsection{Interaction of zincate treatment}

The above-mentioned investigation clarified that the adhesion as well as the morphology of the zinc deposit after the 2nd zincate treatment depended on the type of the acid used for the removal of the zinc deposit after the 1st zincate treatment. It appears that the condition of the substrate surface after the each pickling is intimately related to the form of these zinc deposits. The surface of each aluminum alloy substrate after the different pretreatment shown in Table 2 was investigated by XPS in order to clarify the condition of the substrate surface.

Figure 4 shows the results of the XPS wide spectra for each substrate surface after the different pickling. A description of the XPS wide spectra of each substrate surface dipped in the mixed acid $\left(1 \mathrm{HF}+3 \mathrm{HNO}_{3}\right)$ after the 1 st zincate treatment was omitted, because the same spectra of substrate surface dipped in the mixed acid against the stocks. After the pickling by the mixed acid, aluminum, oxygen, carbon and fluorine derived from the alloy elements and reaction between the aluminum substrate and hydrogen fluoride were detected for each specimen, while copper was detected for only the A2017P alloy. Dissolved copper from the substrate by the pickling was again deposited on the substrate surface to accompany the aluminum dissolution, since the copper standard electrode potential is nobler than that of the aluminum. These deposits acted as nucleation seeds for the deposition of zinc, resulting in uniform, fine and thin zinc deposits. ${ }^{9,11)}$

From the results of each substrate surface after the pickling $\left(5 \% \mathrm{HNO}_{3}\right)$ of the 1 st zincate treatment, zinc was detected together with the foregoing elements. This zinc at the substrate surface should affect the morphology of the zinc deposit for the next zincate treatment, because zinc was not detected at the surface, as the mixed acid $\left(1 \mathrm{HF}+3 \mathrm{HNO}_{3}\right)$ was used instead of the $5 \%$ nitric acid for the pickling, and thus the morphology of the zinc deposit obtained by the zincate treatment, as shown in Fig. 3, became thick and nonuniform. Therefore, an XPS narrow analysis was conducted on the A1100P alloy surface, whose zinc deposits were remarkably changed by the 2 nd zincate treatment, in order to clarify the chemical condition of that surface after the pickling $\left(5 \% \mathrm{HNO}_{3}\right)$ versus the 1 st zincate treatment. Figure 5 shows these results. Argon ion etching was done so as to provide a clean surface, however, the damage for these results was quite small, because the $\mathrm{C} 1 \mathrm{~s}$ peak was detected after this etching. The aluminum peak was due to oxidation and the 


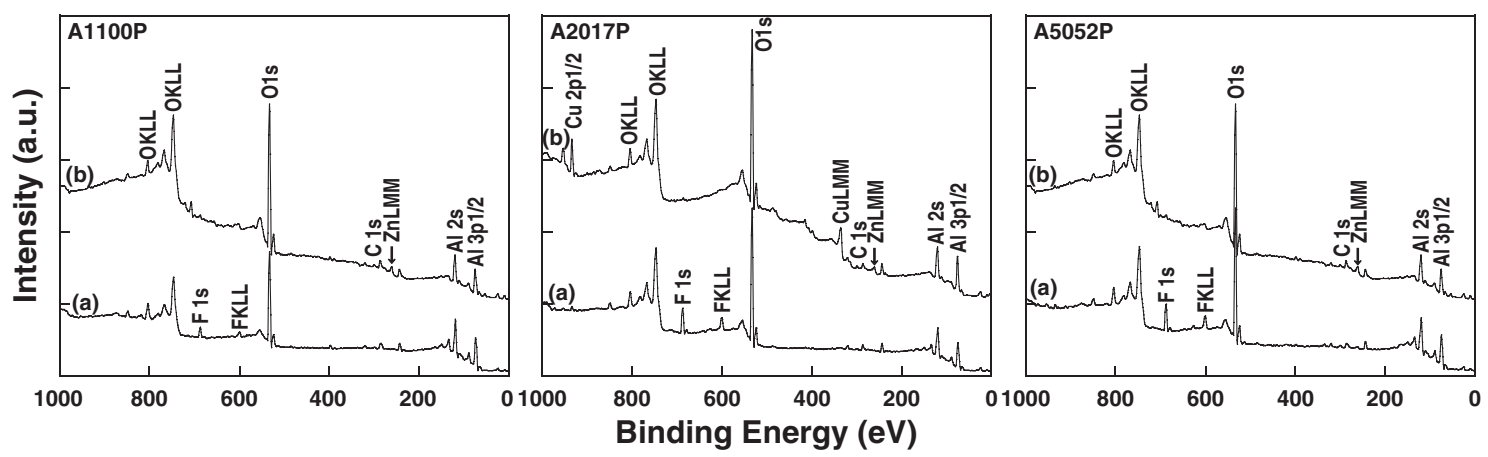

Fig. 4 XPS wide spectra of various aluminum alloys after pickling. (a) Pickling $\left(1 \mathrm{HF}+3 \mathrm{HNO}_{3}\right)$ of the substrate (b) Pickling $\left.(5 \% \mathrm{HNO})\right)$ of the 1 st zincate treatment
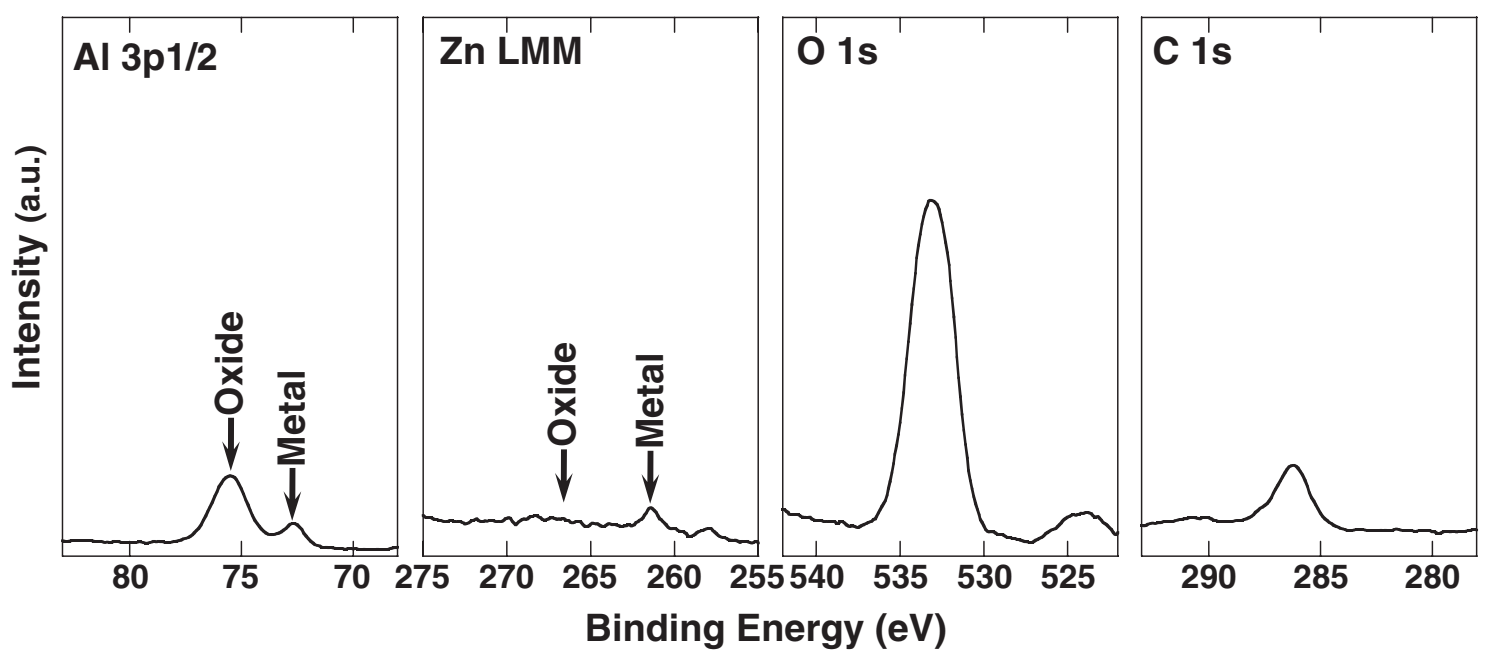

Fig. 5 XPS narrow spectra of $\mathrm{Al}, \mathrm{Zn}, \mathrm{O}$ and $\mathrm{C}$ on $\mathrm{A} 1100 \mathrm{P}$ aluminum alloy after pickling $\left(5 \% \mathrm{HNO}_{3}\right)$ of the 1 st zincate treatment.

metallic state, and the oxidation peak was higher than the metallic peak. This result indicates that the surface of the aluminum substrate is oxidized by the nitric acid used as an oxidizing agent. However, the zinc peak showed only the metallic state irrespective of the dipping in the 5\% nitric acid. Obviously, this zinc, whose state is metallic at the substrate surface, allows the forming of a thinly uniform zinc deposit during the 2 nd zincate treatment, because the zinc deposit became thick and nonuniform by the dipping in the mixed acid or hydrochloric acid instead of the $5 \%$ nitric acid. In spite of the dipping in the $5 \%$ nitric acid as the oxidizing agent, the reason why the zinc in the metallic state exists at the substrate surface is postulated as follows.

Upon zincate treatment, the oxide film initially dissolves as the aluminum substrate was dipped in the zincate solution whose $\mathrm{pH}$ was over 14, and no electron is generated by this reaction. Since aluminum successively dissolves, an electron is generated, and then the displacement reaction of aluminum and zinc can take place. This reaction is finished as the zinc deposit perfectly covers the substrate surface. Therefore, the oxide film hardly occurs at the interface between the aluminum substrate and the zinc deposit, therefore, it seemed easy to diffuse into each other. In the Al-Zn binary phase diagram, ${ }^{12)}$ both the solubility limit of zinc into aluminum and that of aluminum into zinc at room temperature are less than several at.\%, however, the XPS and Field Emission Auger Electron Spectrometer (FE-AES) analyses in previous studies $^{5,7)}$ revealed that aluminum was present at the surface of the zinc deposit after the zincate treatment. This diffusion at room temperature is vigorous at the interface between the aluminum substrate and the zinc deposit, therefore, the aluminum-zinc alloy layer remains at the surface after the dipping in the 5\% nitric acid for zinc removal. At this time, we can consider that the zinc whose condition is a metal, accelerates the oxidation of the aluminum, because the electrochemical potential of the zinc is more noble than that of the aluminum.

Figure 6 shows the results of the XPS Al 3p1/2 narrow spectra of the A1100P alloy surface after pickling in the mixed acid and 5\% nitric acid for zinc removal after the 1 st zincate treatment. The metal peak for the pickling in the mixed acid was high when compared to that for the $5 \%$ nitric acid, and oxide peak for the pickling in the mixed acid was low when compared to that for the $5 \%$ nitric acid. These results supported the foregoing consideration.

In general, the deposited film by displacement plating, such as gold plating, becomes uniformly thin, because the electron is discharged as the less-noble metal substrate dissolves. Subsequently, the metal ion in the solution is reduced by the electron, and this reaction is instantly finished when the deposited film perfectly covers the substrate. However, the morphology of zinc deposit on aluminum alloy substrate by the zincate treatment remarkably changed as shown in Fig. 2 depending on the number of treatments. 


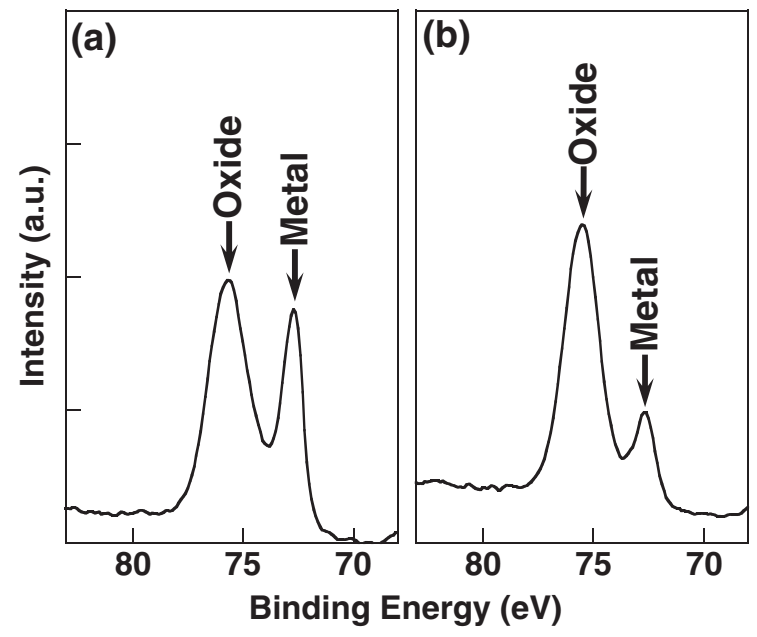

Fig. 6 XPS narrow spectra of $\mathrm{Al} 3 \mathrm{p} 1 / 2$ on A1100P aluminum alloy after various picklings. (a) Pickling $\left(1 \mathrm{HF}+3 \mathrm{HNO}_{3}\right)$ of the substrate (b) Pickling $\left(5 \% \mathrm{HNO}_{3}\right)$ of the 1 st zincate treatment.

Figure 7 shows the cross-sectional SEM images of specimens after the 1 st and 2nd zincate treatments on the A1100P aluminum alloy as shown in Fig. 2. The cross-sectional observation specimens were prepared using the cross section polisher. As shown in Fig. 7(b), the zinc deposit at the surface is rarely observed after the 2 nd zincate treatment, and this fact is explained in terms of the displacement plating idea. On the other hand, after the 1st zincate treatment, a zinc deposit with a remarkable roughness is observed, as shown in Fig. 7(a), and these results well agreed with the surface morphology shown in Fig. 2. This fact is not compatible with the idea of displacement plating. The morphology of the zinc deposit after the 1st zincate treatment can form, as different sites between the anodic dissolution and the deposit by reduction, and this reaction continuously occurs. ${ }^{13)}$ The behavior of this deposit is based on the formation of a nonuniform oxide film on the aluminum substrate. ${ }^{10)}$ Upon zincate treatment, as mentioned earlier, the oxide film initially dissolves. Secondly, as the aluminum dissolves, the electrons are generated, and then the displacement reaction of aluminum and zinc can take place. At this time, the thin weak site of the oxide film first dissolves, if the oxide film is not uniform. This part becomes the anode site, and then the dissolution from the aluminum precedes from the oxide film.
Therefore, the deposit with the remarkable roughness is formed. ${ }^{14)}$ The anodic dissolution of the aluminum after dissolution of the oxide film becomes uniform, so the displacement reaction between the dissolution of the aluminum and the deposition of the zinc ends in a short time, if the oxide film formed on the aluminum substrate is uniform, and that the oxide film uniformly dissolves into the zincate solution. Consequently the zinc deposit from the 2nd zincate treatment seems to become uniformly thin as shown in Fig. 7. Azumi reported by electrochemical measurements that it took approximately 20 seconds to reach the potential of zinc during the 1st zincate treatment, but it took 2 seconds to reach the same potential during the 2 nd zincate treatment. ${ }^{10)}$ These results indicated that the displacement reaction of zinc continued for approximately 20 seconds during the 1 st zincate treatment, and the same reaction came to an end in almost two seconds during the 2 nd zincate treatment. Therefore, these results agree with the foregoing reaction process.

The morphology of the oxide film formed on the aluminum and aluminum alloys seems to depend on the alloying elements and manufacturing process, in particular, this tendency becomes remarkable at the segregated spots and grain boundary. It appears that this foregoing nonuniform oxide film retards the uniformly thin zinc deposit during the 1 st zincate treatment. On the other hand, during the 2nd zincate treatment, the Al-Zn alloy layer at the surface formed by the diffusion between the zinc deposit and aluminum substrate after the 1st zincate treatment seems to relax the nonuniformity of the oxide film depending on the alloying elements and manufacturing process, and so the oxide film formed on the aluminum substrate becomes uniform. Seri reported the relationships between the solid solution quantity of zinc in the aluminum and the standard electrode potential. ${ }^{15}$ The standard electrode potential shifted in the less-noble direction with increase in the solid solution quantity of zinc, and then reached approximately $-1.075 \mathrm{~V}$ for the solid solution quantity of approximately 4 mass $\%$ zinc. The potential decreased $-0.22 \mathrm{~V}$ compared to the pure aluminum, and then the potential did not change for that solid solution quantity or above. The standard electrode potential of aluminum is typically more less-noble than that of zinc, and so the potential due to the solubility of zinc allows the shift in the noble direction, however, these data were not in accord with this result. Therefore, this data suggests that the
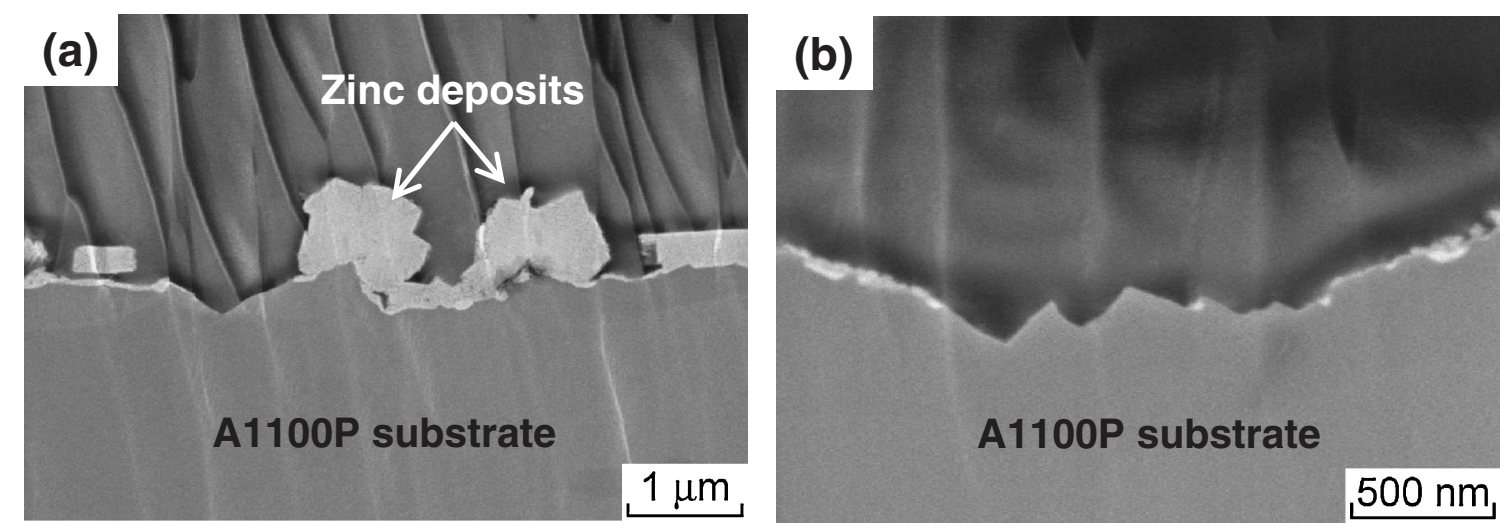

Fig. 7 Cross-sectional SEM images of specimens showing zincate treatment of A1100P aluminum alloy. (a) 1st zincate (b) 2nd zincate. 
oxide film formed on aluminum due to the solubility of zinc becomes thin and fragile, and so the passivation is suppressed. After the 1st zincate treatment, the Al-Zn alloy layer at the surface, which is formed by the diffusion between the zinc deposit and aluminum substrate, seems to suppress passivation of the aluminum substrate, and thus the oxide film immediately dissolves during the 2 nd zincate treatment. Subsequently, the displacement reaction of aluminum and zinc uniformly occurs at the substrate surface, and then the morphology of the zinc deposit from the 2nd zincate treatment should become thin and uniform in this manner.

It was concluded from these results that the Al-Zn alloy layer formed by the diffusion between the zinc deposit and aluminum substrate after the 1 st zincate treatment plays an important role in the uniformly thin zinc deposit from the 2nd zincate treatment.

\section{Conclusions}

This study examined the effects of the zincate treatment and alloying elements on the adhesion of the electroless Ni-P coating on various aluminum alloy substrates. The zinc deposit from the 2nd zincate treatment became thinly uniform, and its adhesive strength was remarkably improved irrespective of the alloying element. It turned out that the morphology of the zinc deposit closely influenced the adhesion. The uniformly thin zinc deposit from the 2nd zincate treatment plays an important role in the zinc existing at the substrate surface after the 1 st zincate treatment and pickling in the $5 \% \mathrm{HNO}_{3}$ solution. It seems that this zinc at the surface can be attributed to the diffusion between the zinc deposit from the 1 st zincate and the aluminum alloy substrate. Thus the Al-Zn alloy layer formed on the aluminum alloy substrate surface after the 1st zincate treatment produced a uniformly thin oxide film, and the passivation was suppressed. Therefore, during the 2nd zincate treatment, the oxide film uniformly dissolves, and the subsequent displacement reaction between the dissolution of the aluminum and the deposition of the zinc ends in a short time, therefore the zinc deposit became highly uniform and thin.

\section{Acknowledgments}

The present authors would like to express their gratitude to Japan KANIGEN Co. Ltd. for providing the solutions for zincate treatment and Ni-P electroless plating.

\section{REFERENCES}

1) M. Shiota: J. Jpn. Inst. Light Met. 55 (2005) 524-528.

2) K. Chiba and K. Toma: J. Jpn. Inst. Light Met. 45 (1995) 355-360.

3) F. Keller and W. G. Zelley: J. Electrochem. Soc. 97 (1950) 143-151.

4) M. Hino, M. Hiramatsu, K. Murakami and T. Kanadani: J. Surf. Fin. Soc. Jpn. 54 (2003) 542-544.

5) M. Hino, K. Murakami, M. Hiramatsu, K. Chen, A. Saijo and T. Kanadani: Mater. Trans. 46 (2005) 2169-2175.

6) M. Hino, K. Murakami, Y. Mitooka, M. Hiramatsu, Y. Miyagawa and T. Kanadani: J. Surf. Fin. Soc. Jpn. 56 (2005) 293-295.

7) K. Murakami, M. Hino, M. Hiramatsu, K. Osamura and T. Kanadani: Mater. Trans. 47 (2006) 2518-2523.

8) M. Hiramatsu, M. Hino and T. Omi: J. Surf. Fin. Soc. Jpn. 48 (1997) 687-691.

9) M. Hino, K. Murakami, T. Mitooka, M. Hiramatsu, T. Nishiyama, K. Hosokawa and T. Kanadani: J. Surf. Fin. Soc. Jpn. 58 (2007) 476-481.

10) K. Azumi, Y. Fujishige, M. Seo, L. Nanis, H. Nakao and M. Tashiro: J. Surf. Fin. Soc. Jpn. 47 (1996) 802-807.

11) K. Azumi, S. Egoshi, S. Kawashima and Y. Koyama: J. Electrochem. Soc. 154(4) (2007) D220-D226.

12) S. A. Mey: Zeitschrift Fuer Metallkunde 84 (1993) pp. 451.

13) M. Tashiro: Hyoumen Gizyutsu Binran, (The Surf. Finish. Soc. Japan, 1998) pp. 383-386.

14) K. Azumi, Y. Fujishige, M. Seo, L. Nanis, H. Nakao and M. Tashiro: J. Surf. Fin. Soc. Jpn. 47 (1996) 529-535.

15) O. Seri: Kinzokuzairyono fushokuto boushokuno kiso, (Seizando, 2006) p. 139. 